\title{
Association of frailty and chemotherapy-related adverse outcomes in geriatric patients with cancer: a pilot observational study in Taiwan
}

\author{
Ya-Wen Ho ${ }^{1,2}$, Woung-Ru Tang ${ }^{2}$, Shih-Ying Chen ${ }^{2}$, Shu-Hui Lee ${ }^{3}$, Jen-Shi Chen ${ }^{1}$, Yu-Shin Hung ${ }^{1}$, \\ Wen-Chi Chou ${ }^{1}$ \\ ${ }^{1}$ Division of Hematology and Oncology, Department of Internal Medicine, Chang Gung Memorial Hospital at \\ Linkou and College of Medicine, Chang Gung University, Taoyuan, Taiwan \\ ${ }^{2}$ School of Nursing, College of Medicine, Chang Gung University, Taoyuan, Taiwan \\ ${ }^{3}$ Department of Nursing, Linkou Chang Gung Memorial Hospital, Chang Gung University of Science and \\ Technology, Cardinal Tien Junior College of Healthcare and Management, Taoyuan, Taiwan
}

Correspondence to: Wen-Chi Chou; email: f12986@cgmh.org.tw

Keywords: chemotherapy-related adverse outcomes, comprehensive geriatric assessment, frailty, geriatric patients with cancer

Received: September 8, $2021 \quad$ Accepted: October 28, $2021 \quad$ Published: November 8, 2021

Copyright: (C) $2021 \mathrm{Ho}$ et al. This is an open access article distributed under the terms of the Creative Commons Attribution License (CC BY 3.0), which permits unrestricted use, distribution, and reproduction in any medium, provided the original author and source are credited.

\section{ABSTRACT}

Background: With the rapid growth of the elderly population and the increasing incidence of cancer, an increasing number of geriatric patients are receiving cancer treatment, making the selection of appropriate treatment an important issue. Increasing studies have confirmed that frailty can predict adverse outcomes in geriatric patients with cancer after treatment, but local data from Taiwan are lacking. Therefore, this study aimed to investigate the correlation between frailty and chemotherapy-related adverse outcomes in geriatric patients with cancer.

Material and Methods: A total of 234 geriatric patients aged $\geq 65$ years with cancer receiving chemotherapy were enrolled during the study period of September 2016 to November 2018. The collected data included: patients' basic demographics and Comprehensive Geriatric Assessment (CGA) before treatment, chemotherapyrelated adverse outcomes, unexpected hospitalizations, and emergency department visits within 3 months of treatment. We investigated the association between frailty and chemotherapy-related adverse outcomes in geriatric patients with cancer using the chi-square test and logistic regression analysis.

Results: The prevalence of frailty in geriatric patients with cancer was $58.1 \%$. Age, marital status, main caregiver, cancer type, and Eastern Cooperative Oncology Group performance status, and physical fitness were factors associated with frailty. Frail geriatric patients with cancer were at higher risk of chemotherapy-related adverse outcomes, such as grades $3-4$ thrombocytopenia (odds ratio [OR] $=11.13, p=0.021$ ) and grades $3-4$ hyponatremia $(O R=12.03, p=0.017)$, than non-frail patients, and they were at increased risk of unexpected hospitalizations $(O R=2.15, p=0.025)$ and emergency department visits $(O R=1.99, p=0.039)$.

Conclusions: Frailty is a common problem in geriatric patients with cancer and significantly impacts chemotherapy-related adverse outcomes. Our findings suggest that geriatric patients with cancer should undergo frail assessment prior to chemotherapy as a reference to guide future treatment decisions. 


\section{INTRODUCTION}

When the proportion of the population aged 65 years or older reaches $7 \%$ of the total population internationally, an "aging society" is created; when it reaches $21 \%$, a "super-aged society" is created [1]. Taiwan officially became an aging society in March 2018 and is expected to become a super-aged society in 2026 due to the dual effects of a declining birth rate and increased aging [1], which shows that the population is changing at a rapid pace. Therefore, the issue of geriatric health care is urgent and important.

Cancer has ranked first among the top 10 causes of death in Taiwan for 38 years in a row [2]. Aging is a high risk factor for cancer [3, 4]. According to the World Health Organization and the International Agency for Research on Cancer, approximately 7 million people aged 65 or older were newly diagnosed with cancer in 2012, and the number of geriatric patients with cancer is expected to reach 14 million by 2035 [4]. Moreover, as many as $70 \%$ of all cancerrelated deaths occur in patients aged 65 or older [5]. This is also the case in Taiwan, where the rate of cancer deaths in elderly individuals aged 65 or older is increasing annually [6]. This indicates that the future care demand for geriatric patients with cancer will pose enormous social and economic challenges.

Cancer treatment for the elderly is complex and requires multiple considerations. Multiple chronic diseases, polypharmacy, and decreased physical fitness due to physiological aging may affect cancer diagnosis and treatment or even increase the risk of treatment [7-9]. However, despite the high incidence of newlydiagnosed cancer in patients over 65 years of age $(51.6 \%)$ [10], geriatric patients are excluded from most oncology studies because of healthcare provider bias, patient age, comorbidity, and poor physical fitness [11, 12]. The lack of guidelines for the treatment of geriatric patients with cancer due to their underrepresentation in clinical trials and the paucity of available empirical data [12] has led to limited anticancer treatment options for geriatric patients with cancer.

Frailty is a popular topic in geriatrics in recent years. Frailty is defined as a decrease in the reserve capacity of the body's multiple systems that increases the risk of adverse health outcomes because the body's adaptability and resilience cannot respond when stressful events occur [13-18]. Frailty can be used to predict chemotherapy-related adverse outcomes such as mortality $[19,20]$, chemotherapy drug tolerance $[16$, 21], severe toxicity [20, 22], treatment interruption, and hospitalization [23] in geriatric patients with cancer undergoing chemotherapy. Therefore, the American
Society of Clinical Oncology [24], National Comprehensive Cancer Network [25], and International Society of Geriatric Oncology [26] state that the Comprehensive Geriatric Assessment (CGA) should be used to assess the frailty of geriatric patients before they receive cancer treatment. The above guidelines, however, are recommendations from Western countries, whereas research on frailty in cancer patients in Taiwan remains in its infancy. Only a few studies have evaluated the association between frailty and chemotherapy-related adverse events in geriatric patients with cancer in Asia [27]. Due to the lack of literature on frailty in local cancer patients, this study aimed to investigate the correlation between frailty and chemotherapy-related adverse outcomes in geriatric patients with cancer in Taiwan for use as a basis for clinical healthcare decisions to improve the safety of treatment of geriatric patients with cancer.

\section{RESULTS}

\section{Patients' basic attributes}

A total of 234 geriatric patients with cancer were enrolled in this study (median age, 70 years; range, 6596 years). The majority of patients were female (53\%), were married $(80.8 \%)$, had solid organ tumors $(67.5 \%)$, had stage III cancer $(40.2 \%)$, and received polypharmacy $(82.9 \%)$. Advanced age, non-married status, non-spouse as the main caregiver, lymphoma, and poor ECOG performance status were significantly associated with patient frailty $(p<0.05)$ (Table 1$)$.

\section{Frailty prevalence and common deficient dimensions}

The prevalence of frailty was $58.1 \%$ among the 234 patients. On the CGA, nutrition (65.4\%) was the most deficient dimension, followed by comorbidity (38.5\%), functional status (24.8\%), and polypharmacy $(23.1 \%)$. Mood (17.5\%), falls (13.2\%), cognition (10.7\%), and social support $(9.4 \%)$ were less often deficient (Table 2 ).

\section{Analysis of frailty and chemotherapy-related adverse outcomes}

The analysis of frailty by level of toxicity showed that among all grades of toxicities, frailty was significantly associated with low hemoglobin $(74.5 \%$ vs $92.6 \%, p<$ $0.001)$, hypokalemia $(8.2 \%$ vs $21.3 \%, p=0.006)$, infection $(17.3 \%$ vs $32.4 \%, p=0.01)$, and neuropathy $(16.3 \%$ vs $35.3 \%, p=0.002)$. In the classification of grade 3-4 toxicity, frailty was significantly associated with thrombocytopenia $(1.0 \%$ vs $10.3 \%, p=0.005)$, any non-hematological toxicity $(25.5 \%$ vs $39.0 \%, p=$ $0.035)$, and hyponatremia (1.0\% vs $11.0 \%, p=0.003)$ (Table 3). 
Table 1. Correlation between basic attributes and frailty of geriatric patients with cancer.

\begin{tabular}{|c|c|c|c|c|}
\hline Variable & $\begin{array}{c}\text { Overall }(N=234) \\
n(\%)\end{array}$ & $\begin{array}{c}\text { Non-frail }(N=98) \\
n(\%)\end{array}$ & $\begin{array}{c}\text { Frail }(N=136) \\
n(\%)\end{array}$ & $P$ \\
\hline Age, Median (range) & $70(65-96)$ & $68(65-85)$ & $72(65-96)$ & 0.007 \\
\hline $65-69$ & $103(44.0)$ & $56(57.1)$ & 47 (34.6) & \\
\hline $70-74$ & 67 (28.6) & $23(23.5)$ & $44(32.4)$ & \\
\hline $75-79$ & $45(19.2)$ & $14(14.3)$ & $31(22.8)$ & \\
\hline$\geq 80$ & $19(8.2)$ & $5(5)$ & $14(10.3)$ & \\
\hline Gender & & & & 0.99 \\
\hline Female & $124(53.0)$ & $52(53.1)$ & $72(52.9)$ & \\
\hline Male & $110(47.0)$ & $46(46.9)$ & $64(47.1)$ & \\
\hline Marriage & & & & 0.014 \\
\hline Married & $189(80.8)$ & $87(88.8)$ & $102(75.0)$ & \\
\hline Others & $45(19.2)$ & $11(11.2)$ & $34(25.0)$ & \\
\hline Education & & & & 0.74 \\
\hline Junior high school or less & $145(62)$ & $59(60.2)$ & $86(63.2)$ & \\
\hline Senior high school or more & $89(38)$ & $39(39.8)$ & $50(36.8)$ & \\
\hline Occupation & & & & 0.85 \\
\hline No & $203(86.8)$ & $86(87.8)$ & $117(86.0)$ & \\
\hline Yes & $31(13.2)$ & $12(12.2)$ & $19(14.0)$ & \\
\hline Main caregiver & & & & 0.047 \\
\hline Spouse & $121(51.7)$ & $60(61.2)$ & $61(44.9)$ & \\
\hline Child & $87(37.2)$ & $29(29.6)$ & $58(42.6)$ & \\
\hline Others & $26(11.1)$ & $9(9.2)$ & $17(12.5)$ & \\
\hline Smoking & & & & 0.99 \\
\hline No & $155(66.2)$ & $65(66.3)$ & $90(66.2)$ & \\
\hline Yes & $79(33.8)$ & $33(36.7)$ & $46(33.8)$ & \\
\hline Drinking & & & & 0.45 \\
\hline No & $165(70.5)$ & $66(67.3)$ & $99(72.8)$ & \\
\hline Yes & $69(29.5)$ & $32(32.7)$ & $37(27.2)$ & \\
\hline ECOG performance & & & & $<0.001$ \\
\hline 0 & $136(58.1)$ & $79(80.6)$ & $57(41.9)$ & \\
\hline 1 & $86(36.8)$ & $19(19.4)$ & $67(49.3)$ & \\
\hline$\geq 2$ & $12(5.2)$ & $0(0.0)$ & $12(8.8)$ & \\
\hline Cancer type & & & & $<0.001 *$ \\
\hline Hematological cancer & $76(32.5)$ & $19(19.4)$ & $57(41.9)$ & $<0.001^{\#}$ \\
\hline Solid cancer & $158(67.5)$ & $79(80.6)$ & $79(58.1)$ & $0.006^{\#}$ \\
\hline Breast & $52(22.2)$ & $31(31.6)$ & $21(15.4)$ & \\
\hline Colorectal & $46(19.7)$ & $22(22.4)$ & $24(17.6)$ & \\
\hline Lung & $12(5.1)$ & $5(5.1)$ & $7(5.1)$ & \\
\hline Stomach & $11(4.7)$ & $5(5.1)$ & $6(4.4)$ & \\
\hline Urogenital & $10(4.3)$ & $3(3.1)$ & $7(5.1)$ & \\
\hline Others & $27(11.5)$ & $13(13.3)$ & $14(10.3)$ & \\
\hline
\end{tabular}




\begin{tabular}{|c|c|c|c|c|}
\hline Stage & & & & 0.07 \\
\hline I & $20(8.5)$ & $7(7.1)$ & $13(9.6)$ & \\
\hline II & $80(34.2)$ & $39(39.8)$ & $41(30.1)$ & \\
\hline III & $94(40.2)$ & $42(42.9)$ & $52(38.2)$ & \\
\hline IV & $40(17.1)$ & $10(10.2)$ & $30(22.1)$ & \\
\hline Chemotherapy regime & & & & $0.99^{*}$ \\
\hline Monotherapy & $40(17.1)$ & $17(17.3)$ & $23(16.9)$ & $0.81^{\#}$ \\
\hline 5-Fluorouracil or capecitabine & $26(11.1)$ & $13(13.3)$ & $13(9.6)$ & \\
\hline Cisplatin & $9(3.8)$ & $4(4.1)$ & $5(3.7)$ & \\
\hline Gemcitabine & $5(2.1)$ & 0 & $5(3.7)$ & \\
\hline Combination therapy & $194(82.9)$ & $81(82.7)$ & $113(83.1)$ & $0.99^{\#}$ \\
\hline R-CHOP & $76(32.8)$ & $19(19.4)$ & $57(41.9)$ & \\
\hline XELOX or FOLFOX & $41(17.5)$ & $19(19.4)$ & $20(14.7)$ & \\
\hline $\mathrm{CEF}$ & $26(11.1)$ & $16(16.3)$ & $8(5.9)$ & \\
\hline $\mathrm{CMF}$ & $25(10.7)$ & $13(13.3)$ & $12(8.8)$ & \\
\hline $\mathrm{GC}$ & $19(8.1)$ & $8(8.1)$ & $11(8.1)$ & \\
\hline Others & $7(3.0)$ & $6(6.1)$ & $1(0.7)$ & \\
\hline
\end{tabular}

Abbreviations: ECOG: Eastern Cooperative Oncology Group; R-CHOP: rituximab plus cyclophosphamide plus doxorubicin plus vincristine plus prednisone; XELOX: capecitabine plus oxaliplatin; FOLFOX: oxaliplatin plus 5-fluorouracil and leucovorin; CEF: cyclophosphamide plus epirubicin plus 5-fluorouracil; CMF: cyclophosphamide plus methotrexate plus 5-fluorouracil; GC: gemcitabine plus cisplatin. ${ }^{*} p$ value for two groups. ${ }^{\#} p$ value for subgroups.

Table 2. Deficient dimensions of the comprehensive geriatric assessment $(N=234)$.

\begin{tabular}{llcccc}
\hline Frailty dimension & \multicolumn{1}{c}{ Measure } & $\begin{array}{c}\text { Number of } \\
\text { items }\end{array}$ & $\begin{array}{c}\text { Score } \\
\text { range }\end{array}$ & $\begin{array}{c}\text { Cutoff } \\
\text { value }\end{array}$ & $N(\%)$ \\
\hline Functional status & ADL & 10 & $0-100$ & $<100$ & $58(24.8)$ \\
Cognition & IADL & 8 & $0-8$ & $<8$ & $25(10.7)$ \\
Nutrition & Modified_short version MMSE & 13 & $0-13$ & $<9$ & $153(65.4)$ \\
Mood & MNA-SF & 6 & $0-14$ & $<12$ & $41(17.5)$ \\
Social support & GDS-4 & 4 & $0-4$ & $>1$ & $22(9.4)$ \\
Polypharmacy & Number of medications & 1 & Yes/No & Yes & $54(23.1)$ \\
Comorbidity & CCI & 1 & $0-\infty$ & $>4$ & $90(38.5)$ \\
Mobility/Falls & Number of falls & 19 & $0-33$ & $>1$ & $31(13.2)$ \\
\hline
\end{tabular}

Abbreviations: ADL: activities of daily living; $\mathrm{CCl}$ : Charlson comorbidity index; GDS: geriatric depression scale; IADL: instrumental activities of daily living; MMSE: mini mental state exam; MNA-SF: mini nutritional assessment-short form.

The logistic regression analysis suggested that frail geriatric patients with cancer were at higher risk of grade 3-4 thrombocytopenia (odds ratio $[\mathrm{OR}]=11.1$; 95\% confidence interval $[\mathrm{CI}], 1.44-86.14 ; p=0.021)$ and grade 3-4 hyponatremia $(\mathrm{OR}=12.0 ; 95 \% \mathrm{CI}, 1.56$ $92.64 ; p=0.017$ ) than those without frailty (Table 4).
In terms of the number of deficient frailty dimensions, when the number was $0,1,2,3,4$, and $\geq 5$, the proportions of grade 3-4 thrombocytopenia were $2.5 \%$, $0 \%, 3.8 \%, 2.4 \%, 32.1 \%$, and $14.3 \%$, respectively ( $p$ for trend < 0.001) (Figure 1); the proportions of grade 3-4 hyponatremia were $0 \%, 1.7 \%, 5.8 \%, 9.5,17.9 \%$, and 
Table 3. Correlation between frailty and chemotherapy-related adverse events $(N=234)$.

\begin{tabular}{|c|c|c|c|c|c|c|}
\hline \multirow[b]{2}{*}{ Adverse events } & \multicolumn{2}{|c|}{ Non-frail $(n=98)$} & \multicolumn{2}{|c|}{ Frail $(n=136)$} & \multirow{2}{*}{$\begin{array}{l}P \text { for all } \\
\text { grades }\end{array}$} & \multirow{2}{*}{$\begin{array}{c}P \text { for } \\
\text { grade } 3-4\end{array}$} \\
\hline & $\begin{array}{c}\text { All grades, } \\
\boldsymbol{n}(\%)\end{array}$ & $\begin{array}{c}\text { Grade 3-4, } \\
\quad n(\%)\end{array}$ & $\begin{array}{c}\text { All grades, } \\
\boldsymbol{n}(\%)\end{array}$ & $\begin{array}{c}\text { Grade 3-4, } \\
n(\%)\end{array}$ & & \\
\hline Any hematological toxicity & $89(90.8)$ & $34(34.7)$ & $131(96.3)$ & $54(39.7)$ & 0.097 & 0.495 \\
\hline Low hemoglobin & $73(74.5)$ & $7(7.1)$ & $126(92.6)$ & $20(14.7)$ & $<0.001$ & 0.097 \\
\hline Thrombocytopenia & $47(48.0)$ & $1(1.0)$ & $69(50.7)$ & $14(10.3)$ & 0.69 & 0.005 \\
\hline Leukopenia & $50(51.0)$ & $16(16.3)$ & $72(52.9)$ & $29(21.3)$ & 0.79 & 0.40 \\
\hline Neutropenia & $59(60.2)$ & $29(29.6)$ & $76(55.9)$ & $45(33.1)$ & 0.59 & 0.67 \\
\hline Neutropenic fever & $5(5.1)$ & $5(5.1)$ & $15(11.0)$ & $15(11.0)$ & 0.15 & 0.15 \\
\hline Any non-hematological toxicity & $94(95.9)$ & $25(25.5)$ & $133(97.8)$ & $53(39.0)$ & 0.46 & 0.035 \\
\hline Excessive AST/ALT & $40(40.8)$ & $1(1.0)$ & $51(37.5)$ & $4(2.9)$ & 0.68 & 0.40 \\
\hline Excessive creatinine & $19(19.4)$ & 0 & $39(28.7)$ & $4(2.9)$ & 0.13 & 0.14 \\
\hline Hyponatremia & $8(8.2)$ & $1(1.0)$ & $24(17.6)$ & $15(11.0)$ & 0.05 & 0.003 \\
\hline Hypokalemia & $8(8.2)$ & $4(4.1)$ & $29(21.3)$ & $10(7.4)$ & 0.006 & 0.405 \\
\hline Hyperglycemia & $30(30.6)$ & $4(4.1)$ & $55(40.4)$ & $12(8.8)$ & 0.13 & 0.195 \\
\hline Oral mucositis & $21(21.4)$ & $1(1.0)$ & $43(31.6)$ & $3(2.2)$ & 0.10 & 0.64 \\
\hline Infection & $17(17.3)$ & $10(10.2)$ & $44(32.4)$ & $26(19.1)$ & 0.01 & 0.068 \\
\hline Hypertension & $83(84.7)$ & $14(14.3)$ & $112(82.4)$ & $19(14)$ & 0.72 & 0.99 \\
\hline Nausea/vomiting & $42(42.9)$ & 0 & $53(39)$ & $3(2.2)$ & 0.59 & 0.27 \\
\hline Fatigue & $41(41.8)$ & $1(1.0)$ & $74(54.4)$ & $1(0.7)$ & 0.06 & 0.99 \\
\hline Diarrhea & $21(21.4)$ & $1(1.0)$ & $31(22.8)$ & $3(2.2)$ & 0.87 & 0.64 \\
\hline Neuropathy & $16(16.3)$ & 0 & $48(35.3)$ & 0 & 0.002 & - \\
\hline
\end{tabular}

For chemotherapy-related adverse outcomes, grade 1-2 toxicity occurred in $20 \%$ or more of patients, or grade $3-4$ toxicity occurs in $5 \%$ or more of patients before being shown in the table above. ${ }^{a}$ Neutropenia in CTCAE has no cases of grade 1-2 toxicity. Abbreviations: AST: aspartate aminotransferase; ALT: alanine aminotransferase.

Table 4. Frailty and risk of chemotherapy-related adverse outcomes.

\begin{tabular}{lccccccc}
\hline Variable & Group & OR $(\mathbf{9 5} \% \mathbf{C I})$ & $\boldsymbol{P}$ & $\mathbf{A O R}^{*}$ & $\boldsymbol{P}$ & AOR $^{\#}$ & $\boldsymbol{P}$ \\
\hline Grade 3-4 & Non-frail & 1 (reference) & & 1 & & 1 & \\
thrombocytopenia & Frail & $11.1(1.44-86.1)$ & 0.021 & $10.2(1.26-90.1)$ & 0.031 & $8.9(1.17-92.4)$ & 0.040 \\
Grade 3-4 & Non-frail & 1 (reference) & & 1 & & 1 & \\
hyponatremia & Frail & $12.0(1.56-92.6)$ & 0.017 & $11.6(1.44-94.1)$ & 0.024 & $9.9(1.40-99.1)$ & 0.036 \\
Unexpected & Non-frail & 1 (reference) & & 1 & & 1 & \\
hospitalizations & Frail & $2.15(1.10-4.17)$ & 0.025 & $2.09(1.06-5.22)$ & 0.032 & $1.87(1.03-6.29)$ & 0.043 \\
Emergency department & Non-frail & 1 (reference) & & 1 & & 1 & \\
visits & Frail & $1.99(1.03-3.82)$ & 0.039 & $1.72(1.01-3.22)$ & 0.045 & $1.49(1.00-4.21)$ & 0.048 \\
\hline
\end{tabular}

Abbreviations: $\mathrm{Cl}$ : confidence interval; OR: odds ratio; AOR: Adjusted odds ratio. ${ }^{*}$ Adjusted for age and gender. ${ }^{*}$ Adjusted for age, gender, cancer types, and chemotherapy regimens. 
$21.4 \%$, respectively ( $p$ for trend $<0.001$ ) (Figure 2). This showed that the incidence of grade 3-4 thrombocytopenia and hyponatremia increased significantly with the number of deficient frailty dimensions.

\section{Analysis of frailty, unexpected hospitalizations, and emergency department visits}

The prevalence of unexpected hospitalizations and emergency department visits within 3 months of treatment was $22.6 \%$ and $23.1 \%$, respectively. The incidence of unexpected hospitalizations was $15.3 \%$ in the non-frail group and $27.9 \%$ in the frail group, which indicated that frail patients were at higher risk of unexpected hospitalizations than non-frail patients (OR $=2.15 ; 95 \%$ CI, 1.10-4.17; $p=0.025$ ) (Table 4). For patients with hospitalization, the median length of hospital stay was 8 days (range, 1-26) and 14 days (range, 1-45) for fit and frail patients $(p=0.058)$, respectively. The incidence of emergency department visits was $16.3 \%$ and $27.9 \%$ in the non-frail and frail groups, respectively, suggesting that frail patients were at higher risk of emergency department visits than nonfrail patients $(\mathrm{OR}=1.99 ; 95 \% \mathrm{CI}, 1.03-3.82 ; p=$ 0.039). The adjusted ORs among each adverse event remain had significant in-groups difference after adjusting for age, gender, cancer types, and chemotherapy regimens.

\section{DISCUSSION}

The present study aimed to examine the association between frailty and chemotherapy-related adverse outcomes among geriatric patients with cancer in Taiwan. Frailty was a common problem in geriatric patients with cancer at a prevalence of 58\%. In addition, the risk of chemotherapy-related adverse outcomes, including chemotherapy toxicity, unexpected hospitalizations, and emergency department visits, was significantly higher among frail geriatric patients with cancer when undergoing curative high-intensity chemotherapy than non-frail geriatric patients with cancer. This study is the first of its kind in Taiwan to examine the prevalence of frailty and association of frailty and chemotherapy-related adverse outcomes in geriatric patients with cancer. Our findings suggest that frailty assessments should be performed before geriatric patients with cancer receive chemotherapy. This assists with the early detection of high-risk patients prone to chemotherapy-related adverse outcomes, which not only provides early psychological preparation for patients and their families, it helps healthcare professionals intervene early to prevent the occurrence of adverse outcomes.

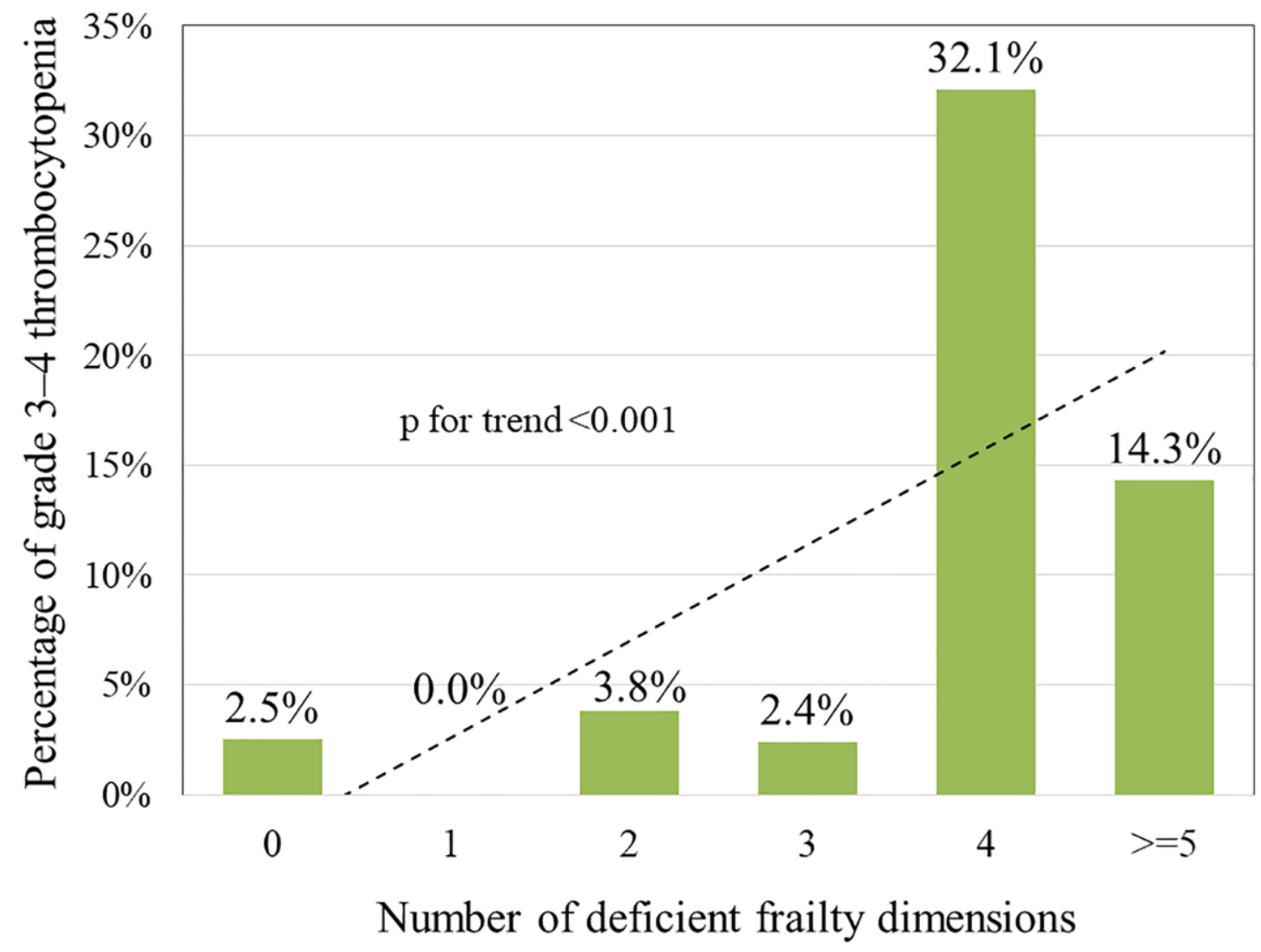

Figure 1. Correlation between number of deficient frailty dimensions and grades 3-4 thrombocytopenia. 
An estimated $58 \%$ of our geriatric patients with cancer suffered from frailty. A retrospective systemic review showed a $43 \%$ median prevalence (range, 7-68\%) of frailty in geriatric patients with cancer [21], significantly lower than that in the present study. Of the 16 papers reviewed in this study that used CGA for frailty identification, most assessed CGA in 6-7 dimensions and defined frailty as $\geq 2$ deficient dimensions [21]. The present study used the same cutoff criteria, but its inclusion of more (eight) dimensions in the CGA assessment may have contributed to the higher prevalence of frailty than reported by previous studies.

Age, marital status, main caregiver, and cancer type were correlated with frailty in the present study. Age is the most widely known correlate of frailty, and the individual physical function, psychological function, and social support inevitably deteriorate with aging [28], making frailty assessments and timely interventions paramount for geriatric patients. The high proportion of frail patients who are single and whose main caregiver is not their spouse indicates that family support, especially care from a spouse, is crucial for geriatric patients with cancer. This study showed that geriatric patients with hematological cancers had significantly higher rates of frailty than those with solid tumors ( $75 \%$ vs $50 \%)$. We further analyzed that $45 \%$ of patients with hematological cancers were $\geq 75$ years old (compared with $19 \%$ of patients with solid tumors), while $42 \%$ had stage IV cancer (compared with $5 \%$ of patients with solid tumors), which may account for the difference in frailty rates. Moreover, the differences in staging and treatment between hematological cancers and solid tumors were so dramatic that more studies are needed to confirm the results of this study and demonstrate whether patients with hematologic cancers are at higher risk of frailty.

Our results showed that poor ECOG performance status was also a risk factor for frailty. Performance is now commonly used in clinical practice to assess the physical fitness of cancer patients as a reference for cancer treatment [29]. Although the ECOG assessment is easy to use, it is too simplified and easily influenced by assessor subjectivity [30,31]. In this study, patients with an ECOG performance status $\geq 2$ accounted for only $5.2 \%$, but those with physical impairment (activities of daily living [ADL] or instrumental ADL [IADL] deficiency) reached $24.8 \%$, indicating that ECOG may not be an appropriate indicator for physical fitness assessments in geriatric patients. In addition to using ECOG as a simple physical fitness assessment for cancer patients, ADL or IADL should be performed as a

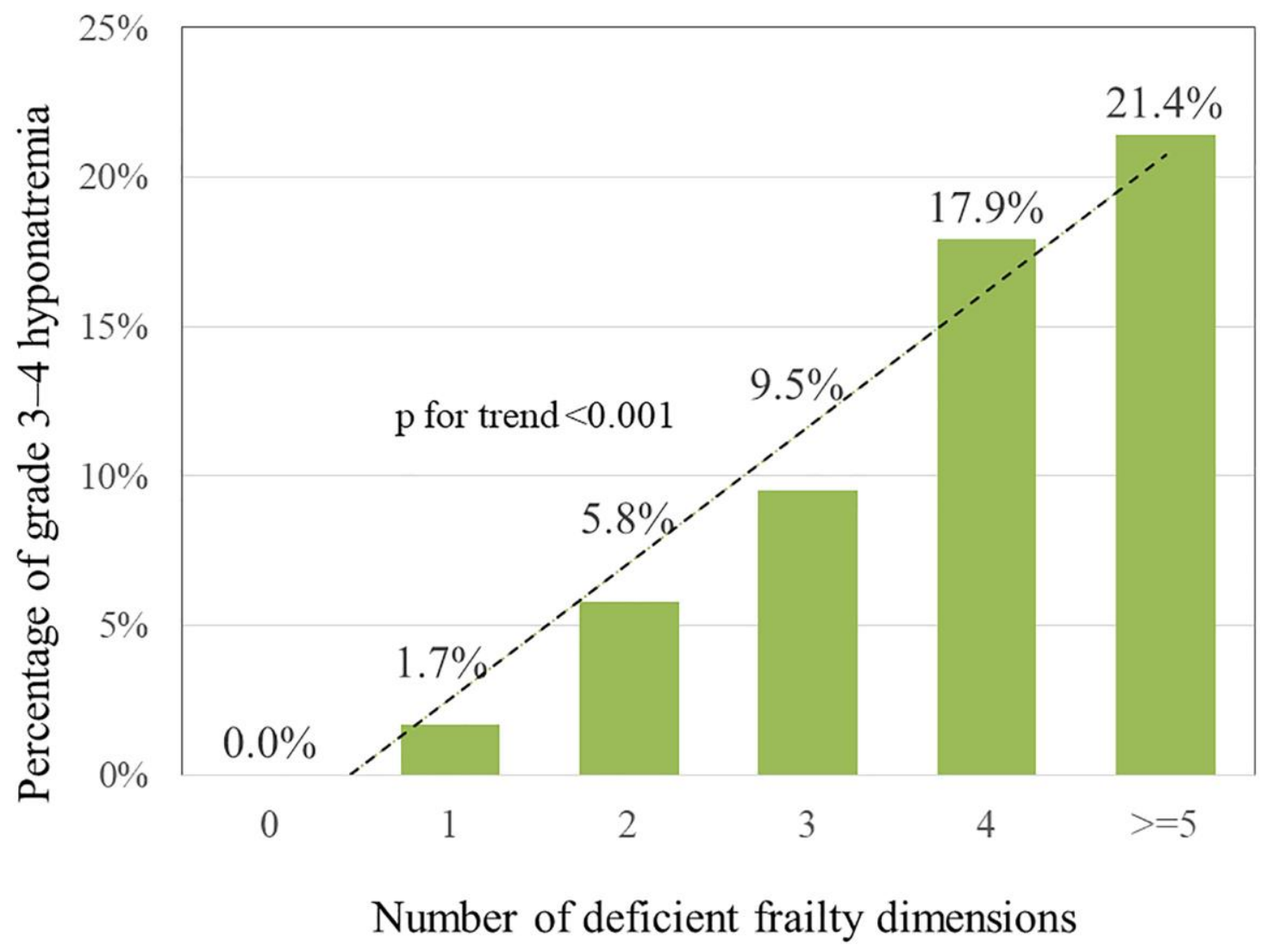

Figure 2. Correlation between number of deficient frailty dimensions and grade 3-4 hyponatremia. 
physical fitness assessment for geriatric patients with cancer in the future to better predict their frailty and chemotherapy risk.

Similar to previous literature, frailty had a significant impact on the occurrence of grade 3 or above serious adverse outcomes in our cohort [23, 32-35]. The association of grade 3 or above toxicity with frailty has been studied in the literature, but less severe chemotherapy toxicity is also important for geriatric patients with cancer. Grade 1-2 toxicity (hypokalemia and neuropathy) was also associated with frailty in our study. Therefore, for geriatric patients with frailty, the development of less severe toxicity should also be considered, and the treatment regimen should be adjusted promptly to avoid increasing the subsequent damage of the side effects of anticancer treatment, thus improving drug safety and patient quality of life. Contrastingly, some studies indicated that frailty was not associated with the side effects of chemotherapy [36-38]. This may be due to the fact that the study was a pilot trial conducted in older newly-diagnosed cancer patients receiving different antitumor strategies and its findings may not be applicable to geriatric cancer patients underwent chemotherapy [38], the low intensity of chemotherapy received by the study participants [36], and the small number of participants but comparison between multiple groups of frailty, all of which may diminish the number of cases in each group and the failure to achieve significance in the statistical analysis [37].

In the analysis of frailty, unexpected hospitalizations, and emergency department visits, this study revealed that the incidence of unexpected hospitalizations and emergency department visits was higher among frail patients than among non-frail patients, which was concurred with the findings of previous studies [23, 32, 38]. The cumulative effect of negative factors such as older age, poorer physical fitness, and weak family support systems led to higher incidence and severity of CTCAE in frail patients, which resulted in an increased incidence of unexpected hospitalizations and emergency department visits. In this way, appropriate interventions should be provided to improve the frailty of elderly and frail patients before versus after anticancer treatment, and close attention should be paid to the assessment and management of the side effects of chemotherapy to reduce the incidence of serious adverse outcomes.

In published literature, frailty is commonly quantified by counting the number of deficits, including disability, disease, psychosocial distress, and cognitive impairments [16, 24]. The Frailty index (FI), ranging from 0 to 1 , is calculated by dividing the number of deficits by the total numbers of variables measured [17]. The index has the advantage because it is constructed from different clinical variables that are relevant to the specific clinical settings, and because the outcome measure has continuous values [39]. However, since the optimal cut-off value of FI might vary among different outcome measures, the clinical application for cancer patients undergoing specific treatment may be limited to specific settings. In the current study, we successfully applied an eight-dimension CGA to identify frail patients who are at the highest risk of adverse outcomes during the chemotherapy course, suggesting that CGA is a useful assessment tool for frailty in Taiwanese geriatric cancer patients. However, there is no consensus on the cutoff level of the numbers and aspects of geriatric domain impairment for CGA in Asian cancer patients. The optimal instruments of CGA suitable for the Asian oncogeriatric population are needed for further exploration and validation.

There are some limitations in this study, including the large number of cancer types enrolled in this study, the wide variation in chemotherapy treatments for different cancer types, and the limitation of the enrollment site to a medical center in northern Taiwan. The provision of healthcare may vary across countries, regions, and hospitals, which can limit the inference of the results. Although the $\mathrm{p}$ for trend had a significant association between grade 3-4 thrombocytopenia and numbers of deficient frailty dimensions in our study. These two parameters did not present a linear association in our study. The possible explanation might be because of the small numbers of the event, accounting for only 15 of 234 patients (6.4\%) had grade 3-4 thrombocytopenia, in our study. Similarly, the wide confidence interval of odds ratio in risk of chemotherapy-related adverse outcomes indicated either the rare incidence of the events or small numbers of patients, therefore, more patient numbers are necessary to recruit to validate our data. The chemotherapy toxicity of patients in this study was determined by the treating physicians of different departments based on the CTCAE, which is more subjective for judging the adverse outcomes of nontested values; thus, the incidence and severity of these non-tested values may have been underestimated. Future studies may incorporate the Patient Reported Outcomes-CTCAE) developed by the NCI [40] to eliminate the subjective bias in the definition of side effects by different healthcare professionals.

In conclusion, this study is one of the first studies in Taiwan to investigate the effect of frailty on chemotherapy-related adverse outcomes in geriatric patients with cancer. It revealed a significant effect of frailty on chemotherapy-related adverse outcomes in 
geriatric patients with cancer. Our findings suggest that frail assessments be conducted before chemotherapy is administered to geriatric patients with cancer in the future. This information will give clinical staff more references when discussing treatment decisions with patients, thus enhancing the quality of care for geriatric patients with cancer in Taiwan.

\section{MATERIALS AND METHODS}

\section{Participants and data collection}

This study was part of a large-scale prospective, longitudinal, and observational study in which data were collected through a structured questionnaire. The study site was a medical center in northern Taiwan. Inclusion criteria were: (1) age $\geq 65$ years and ready to receive chemotherapy with curative intent; (2) have a clear mind and the ability to communicate verbally or in writing; and (3) willingness to sign the respondent's consent form. The study was approved by the Institutional Review Board (no. 201600916B0). The basic attributes of the participants in the week before treatment were collected, including sex, age, marital status, education, occupation, main caregiver, cancer type, cancer stage, Eastern Cooperative Oncology Group (ECOG) performance status, chemotherapy regimen, smoking history, and drinking history. Data on chemotherapy-related adverse outcomes, unexpected hospitalizations, and emergency department visits within 3 months of treatment were also collected for analysis.

\section{Comprehensive geriatric assessment}

All patients were assessed with the Comprehensive Geriatric Assessment (CGA) in person by two research assistants with medical management and nursing backgrounds based on a daily working within one week before initiation of chemotherapy. The CGA assessment dimensions in this study included: functional status [41, 42], cognition [43], nutrition [44], mood [45], social support [46], polypharmacy [25], comorbidity [47], and falls [24]. Based on our previous validation study using the same assessment tool in a Taiwanese adult cancer population, frailty in this study was defined as the presence of two or more frail conditions [48]. The assessment tools and cut-off points for each dimension are presented in Table 2.

\section{Chemotherapy-related adverse outcomes, unexpected hospitalizations, and emergency department visits}

In this study, chemotherapy-related adverse outcomes were evaluated within 3 months of treatment according to the Common Terminology Criteria for Adverse Events (CTCAE) version 4.0 [49] published by the National Cancer Institute (NCI). The CTCAE has five levels of severity, with a higher level indicating more severe side effects (toxicity) experienced by the patient. The study also collected data on whether patients had unexpected hospitalizations and emergency department visits within 3 months of treatment.

\section{Statistical analysis}

We adopted the chi-square test to analyze the correlation between basic patient attributes and frailty as well as the correlation between frailty and chemotherapy-related adverse outcomes. The variables showing significant correlations between frailty and chemotherapy-related adverse outcomes were then subjected to binary logistic regression analysis to understand the association between frailty and chemotherapy-related adverse outcomes, unexpected hospitalizations (yes/no), and emergency department visits (yes/no).

Chemotherapy-related adverse outcomes were analyzed in three different classifications: all grades (with/without toxicity), grades 1-2 (with/without grade 1-2 toxicity), and grades 3-4 (with/without grade 1-2 toxicity) to examine the performance of frailty according to different grades of toxicity. The data were analyzed using the SPSS 20.0 for Windows statistical software package, and all statistical analyses were twotailed, with values of $p<0.05$ considered statistical significance.

\section{Ethics approval and consent to participate}

This study was approved by the institutional review board of Chang Gung Memorial Hospital in August 2017 (ethic code: 1608080002) and has been conducted in compliance with the Helsinki Declaration (1996).

\section{Availability of supporting data}

The datasets used and/or analyzed during the current study are available from the corresponding author on reasonable request.

\section{AUTHOR CONTRIBUTIONS}

Conception and design of study: YWH, WRT, SYC, CWC; Acquisition of data: YWH, SYC, SHL, JSC; Analysis and interpretation of data: YWH, SYC, WRT, YSH, CWC; Drafting of the manuscript: YWH, WRT, SYC, SHL, JSC, YSH, CWC. 


\section{ACKNOWLEDGMENTS}

The authors gratefully acknowledge the support from the Cancer Center of Chang Gung Memorial Hospital, Taoyuan, Taiwan.

\section{CONFLICTS OF INTEREST}

The authors declare no conflicts of interest related to this study.

\section{FUNDING}

This research was not funded by any public, commercial, or nonprofit agencies.

\section{REFERENCES}

1. Department of Human Resources Development. Population Projections for the Republic of China (Taiwan): 2018-2065. National Development Council. 2018. https://ws.ndc.gov.tw/Download.ashx?u=LzAwMS9h ZG1pbmlzdHJhdG9yLzExL3JlbGZpbGUvNTU4OS8xMjk zLzdhOWRmMjhILTgwYzUtNGY2Ny1iZjkxLTdkMGEzN WQ3NjMzZC5wZGY\%3d\&n=MTA354ml5Lq65Y\%2bj5o 6o5Lyw57Ch5aCx77yaMjAxOH4yMDY1LeiLseaWh\%2 beJiChQZXRIcueJiClmaW5hbC5wZGY\%3d\&icon=.pdf.

2. Republic of China: Bureau of Health Promotion, Department of Health, Executive Yuan. Cancer registry annual report, 2017 Taiwan. Health Promotion Administration Ministry of Health and Welfare Taiwan. 2019. https://www.hpa. gov.tw/Pages/ashx/File.ashx?FilePath= /File/Attach/ 12235/File 13854.pdf.

3. Cinar D, Tas D. Cancer in the elderly. North Clin Istanb. 2015; 2:73-80. https://doi.org/10.14744/nci.2015.72691 PMID:28058345

4. Pilleron S, Sarfati D, Janssen-Heijnen M, Vignat J, Ferlay J, Bray F, Soerjomataram I. Global cancer incidence in older adults, 2012 and 2035: A population-based study. Int J Cancer. 2019; 144:49-58.

https://doi.org/10.1002/ijc.31664

PMID:29978474

5. National Cancer Institute. SEER Cancer Statistics Review 1975-2017. 2021. https://seer.cancer.gov/ csr/1975 2017/results single/sect 01 table.12 2pgs. pdf.

6. Ministry of Health and Welfare. 2019 cause of death statistic. 2020. https://www.mohw.gov.tw/cp-496455572-2.html.

7. Chou WC, Liu KH, Lu CH, Hung YS, Chen MF, Cheng YF, Wang $\mathrm{CH}$, Lin YC, Yeh TS. To Operate or Not:
Prediction of 3-Month Postoperative Mortality in Geriatric Cancer Patients. J Cancer. 2016; 7:14-21. https://doi.org/10.7150/jca.13126 PMID:26722355

8. Goh I, Lai O, Chew L. Prevalence and Risk of Polypharmacy Among Elderly Cancer Patients Receiving Chemotherapy in Ambulatory Oncology Setting. Curr Oncol Rep. 2018; 20:38. https://doi.org/10.1007/s11912-018-0686-x PMID:29582192

9. Sarfati D, Koczwara B, Jackson C. The impact of comorbidity on cancer and its treatment. CA Cancer J Clin. 2016; 66:337-50. https://doi.org/10.3322/caac.21342 PMID:26891458

10. Global Cancer Observatory. Estimated number of new cases in 2020, worldwide, both sexes, ages 65+. 2020. https://gco.iarc.fr/today/online-analysistable? $\mathrm{v}=2020 \&$ mode $=$ cancer $\&$ mode population $=$ con tinents \&population $=900 \&$ populations $=900 \&$ key $=a s r$ \&sex $=0 \&$ cancer $=39 \&$ type $=0 \&$ statistic $=5 \&$ prevalence $=$ 0\&population group=0\&ages group $\% 5 \mathrm{~B} \% 5 \mathrm{D}=13 \& \mathrm{ag}$ es group $\% 5 \mathrm{~B} \% 5 \mathrm{D}=17 \&$ group cancer $=1 \&$ include $\mathrm{nm}$ sc=1\&include nmsc other $=1$.

11. Denson AC, Mahipal A. Participation of the elderly population in clinical trials: barriers and solutions. Cancer Control. 2014; 21:209-14. https://doi.org/10.1177/107327481402100305 PMID:24955704

12. Marosi C, Köller M. Challenge of cancer in the elderly. ESMO Open. 2016; 1:e000020. https://doi.org/10.1136/esmoopen-2015-000020 PMID:27843603

13. Abellan van Kan G, Rolland YM, Morley JE, Vellas B. Frailty: toward a clinical definition. J Am Med Dir Assoc. 2008; 9:71-2.

https://doi.org/10.1016/i.jamda.2007.11.005 PMID:18261696

14. Clegg A, Young J, lliffe S, Rikkert MO, Rockwood K. Frailty in elderly people. Lancet. 2013; 381:752-62. https://doi.org/10.1016/s0140-6736(12)62167-9 PMID:23395245

15. De Lepeleire J, lliffe S, Mann E, Degryse JM. Frailty: an emerging concept for general practice. Br J Gen Pract. 2009; 59:e177-82. https://doi.org/10.3399/bjgp09X420653 PMID:19401013

16. Ethun CG, Bilen MA, Jani AB, Maithel SK, Ogan K, Master VA. Frailty and cancer: Implications for oncology surgery, medical oncology, and radiation oncology. CA Cancer J Clin. 2017; 67:362-77. 
https://doi.org/10.3322/caac.21406

PMID:28731537

17. Fried LP, Tangen CM, Walston J, Newman AB, Hirsch C, Gottdiener J, Seeman T, Tracy R, Kop WJ, Burke G, McBurnie MA, and Cardiovascular Health Study Collaborative Research Group. Frailty in older adults: evidence for a phenotype. J Gerontol A Biol Sci Med Sci. 2001; 56:M146-56.

https://doi.org/10.1093/gerona/56.3.m146

PMID: 11253156

18. Junius-Walker $U$, Onder G, Soleymani D, Wiese B, Albaina O, Bernabei R, Marzetti E, and ADVANTAGE JA WP4 group. The essence of frailty: A systematic review and qualitative synthesis on frailty concepts and definitions. Eur J Intern Med. 2018; 56:3-10.

https://doi.org/10.1016/j.ejim.2018.04.023

PMID:29861330

19. Chou WC, Chang $\mathrm{H}$, Wang PN, Kuo MC, Wu JH, Lin TL, Su YJ, Kao HW, Ou CW, Hung CY, Hsueh SW, Hung YS. Application of comprehensive geriatric assessment in predicting early mortality among elder patients with B-cell lymphoma receiving immunochemotherapy. Eur J Haematol. 2020; 105:399-407. https://doi.org/10.1111/ejh.13457 PMID: $\underline{32472712}$

20. Retornaz F, Guillem O, Rousseau F, Morvan F, Rinaldi Y, Nahon S, Castagna C, Boulahssass R, Grino M, Gholam D. Predicting Chemotherapy Toxicity and Death in Older Adults with Colon Cancer: Results of MOST Study. Oncologist. 2020; 25:e85-93.

https://doi.org/10.1634/theoncologist.2019-0241 PMID: 31387952

21. Handforth C, Clegg A, Young C, Simpkins S, Seymour MT, Selby PJ, Young J. The prevalence and outcomes of frailty in older cancer patients: a systematic review. Ann Oncol. 2015; 26:1091-101.

https://doi.org/10.1093/annonc/mdu540

PMID:25403592

22. Runzer-Colmenares FM, Urrunaga-Pastor D, RocaMoscoso MA, De Noriega J, Rosas-Carrasco O, Parodi JF. Frailty and Vulnerability as Predictors of Chemotherapy Toxicity in Older Adults: A Longitudinal Study in Peru. J Nutr Health Aging. 2020; 24:966-72.

https://doi.org/10.1007/s12603-020-1404-6 PMID:33155622

23. Cohen HJ, Smith D, Sun CL, Tew W, Mohile SG, Owusu C, Klepin HD, Gross CP, Lichtman SM, Gajra A, Filo J, Katheria V, Hurria A, and Cancer and Aging Research Group. Frailty as determined by a comprehensive geriatric assessment-derived deficit-accumulation index in older patients with cancer who receive chemotherapy. Cancer. 2016; 122:3865-72. https://doi.org/10.1002/cncr.30269

PMID:27529755

24. Mohile SG, Dale W, Somerfield MR, Schonberg MA, Boyd CM, Burhenn PS, Canin B, Cohen HJ, Holmes HM, Hopkins JO, Janelsins MC, Khorana AA, Klepin $H D$, et al. Practical Assessment and Management of Vulnerabilities in Older Patients Receiving Chemotherapy: ASCO Guideline for Geriatric Oncology. J Clin Oncol. 2018; 36:2326-47. https://doi.org/10.1200/ico.2018.78.8687 PMID:29782209

25. National Comprehensive Cancer Network. NCCN Clinical Practice Guideline in Oncology. Older Adult Oncology, Version 1. https://www.nccn.org/ professionals/physician gls/pdf/senior.pdf. 2020.

26. International Society of Geriatric Oncology. Practice guideline: comprehensive geriatric assessment (CGA) in oncological patients. http://siog.org/files/public/ cga practice guideline wildiers jul2011.pdf. 2011.

27. Wang $Y$, Zhang $R$, Shen $Y$, Su L, Dong B, Hao Q. Prediction of chemotherapy adverse reactions and mortality in older patients with primary lung cancer through frailty index based on routine laboratory data. Clin Interv Aging. 2019; 14:1187-97.

https://doi.org/10.2147/CIA.S201873

PMID:31308642

28. Niederstrasser NG, Rogers NT, Bandelow S. Determinants of frailty development and progression using a multidimensional frailty index: Evidence from the English Longitudinal Study of Ageing. PLoS One. 2019; 14:e0223799.

https://doi.org/10.1371/journal.pone.0223799 PMID:31665163

29. Orr ST, Aisner J. Performance status assessment among oncology patients: a review. Cancer Treat Rep. 1986; 70:1423-9.

PMID:3539328

30. Chow R, Chiu N, Bruera E, Krishnan M, Chiu L, Lam H, DeAngelis C, Pulenzas N, Vuong S, Chow E. Inter-rater reliability in performance status assessment among health care professionals: a systematic review. Ann Palliat Med. 2016; 5:83-92.

https://doi.org/10.21037/apm.2016.03.02 PMID:27121736

31. Simcock R, Wright J. Beyond Performance Status. Clin Oncol (R Coll Radiol). 2020; 32:553-61.

https://doi.org/10.1016/j.clon.2020.06.016 PMID: 32684503

32. Aparicio T, Jouve JL, Teillet L, Gargot D, Subtil F, Le Brun-Ly V, Cretin J, Locher C, Bouché O, Breysacher G, Charneau J, Seitz JF, Gasmi M, et al. Geriatric factors predict chemotherapy feasibility: ancillary results of 
FFCD 2001-02 phase III study in first-line chemotherapy for metastatic colorectal cancer in elderly patients. J Clin Oncol. 2013; 31:1464-70.

https://doi.org/10.1200/jco.2012.42.9894

PMID:23460711

33. Hamaker ME, Seynaeve C, Wymenga AN, van Tinteren $\mathrm{H}$, Nortier JW, Maartense E, de Graaf $\mathrm{H}$, de Jongh FE, Braun JJ, Los M, Schrama JG, van LeeuwenStok $A E$, de Groot SM, Smorenburg $\mathrm{CH}$. Baseline comprehensive geriatric assessment is associated with toxicity and survival in elderly metastatic breast cancer patients receiving single-agent chemotherapy: results from the OMEGA study of the Dutch breast cancer trialists' group. Breast. 2014; 23:81-7.

https://doi.org/10.1016/i.breast.2013.11.004

PMID:24314824

34. van der Vlies E, Kurk SA, Roodhart JML, Gerritse FL, Pelgrim TC, Vos JM, Sohne M, Hunting CB, Noordzij PG, van der Velden AMT, Los $M$. The relevance of geriatric assessment for older patients receiving palliative chemotherapy. J Geriatr Oncol. 2020; 11:482-7.

https://doi.org/10.1016/j.jgo.2019.05.016 PMID:31160210

35. Wildes TM, Ruwe AP, Fournier C, Gao F, Carson KR, Piccirillo JF, Tan B, Colditz GA. Geriatric assessment is associated with completion of chemotherapy, toxicity, and survival in older adults with cancer. J Geriatr Oncol. 2013; 4:227-34.

https://doi.org/10.1016/j.jgo.2013.02.002

PMID:23795224

36. Karampeazis A, Vamvakas L, Agelaki S, Xyrafas A, Pallis A, Saloustros E, Giannousi Z, Kalbakis K, Mavroudis D, Georgoulias V. Baseline comprehensive geriatric assessment (CGA) and prediction of toxicity in elderly non-small cell lung cancer (NSCLC) patients receiving chemotherapy. J Clin Oncol. 2011; 29:e19656.

https://doi.org/10.1200/jco.2011.29.15 suppl.e19656

37. Moth EB, Kiely BE, Stefanic N, Naganathan V, Martin A, Grimison P, Stockler MR, Beale P, Blinman P. Predicting chemotherapy toxicity in older adults: Comparing the predictive value of the CARG Toxicity Score with oncologists' estimates of toxicity based on clinical judgement. J Geriatr Oncol. 2019; 10:202-9.

https://doi.org/10.1016/j.jgo.2018.08.010

PMID:30224184

38. Puts MT, Monette J, Girre V, Wolfson C, Monette M, Batist G, Bergman H. Does frailty predict hospitalization, emergency department visits, and visits to the general practitioner in older newlydiagnosed cancer patients? Results of a prospective pilot study. Crit Rev Oncol Hematol. 2010; 76:142-51.

https://doi.org/10.1016/j.critrevonc.2009.10.006 PMID:19939699

39. McCarthy AL, Peel NM, Gillespie KM, Berry R, Walpole $E$, Yates $P$, Hubbard RE. Validation of a frailty index in older cancer patients with solid tumours. BMC Cancer. 2018; 18:892.

https://doi.org/10.1186/s12885-018-4807-6

PMID:30217171

40. National Cancer Institute. PRO-CTCAE ${ }^{\mathrm{TM}}$ Measurement System. 2020. https://healthcaredelivery.cancer.gov/ pro-ctcae/pro-ctcae chinese-traditional.pdf.

41. Lawton MP, Brody EM. Assessment of older people: self-maintaining and instrumental activities of daily living. Gerontologist. 1969; 9:179-86.

https://doi.org/10.1093/geront/9.3 Part 1.179 PMID: $\underline{5349366}$

42. Mahoney FI, Barthel DW. Functional evaluation: The barthel index. Md State Med J. 1965; 14:61-5. PMID: 14258950

43. Schultz-Larsen K, Lomholt RK, Kreiner S. Mini-Mental Status Examination: a short form of MMSE was as accurate as the original MMSE in predicting dementia. J Clin Epidemiol. 2007; 60:260-7. https://doi.org/10.1016/j.jclinepi.2006.06.008 PMID: 17292020

44. Rubenstein LZ, Harker JO, Salvà A, Guigoz Y, Vellas B. Screening for undernutrition in geriatric practice: developing the short-form mini-nutritional assessment (MNA-SF). J Gerontol A Biol Sci Med Sci. 2001; 56:M366-72.

https://doi.org/10.1093/gerona/56.6.m366 PMID:11382797

45. D'Ath $\mathrm{P}$, Katona $\mathrm{P}$, Mullan E, Evans $\mathrm{S}$, Katona C. Screening, detection and management of depression in elderly primary care attenders. I: The acceptability and performance of the 15 item Geriatric Depression Scale (GDS15) and the development of short versions. Fam Pract. 1994; 11:260-6.

https://doi.org/10.1093/fampra/11.3.260

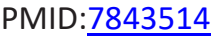

46. Mouodi S, Bijani A, Hosseini SR, Hajian-Tilaki K. Gender differences in the health status of elderly living alone compared to those who are not alone: Evidence of the AHAP study, North of Iran. Caspian J Intern Med. 2016; 7:126-32.

PMID:27386065

47. Charlson ME, Pompei $P$, Ales KL, MacKenzie CR. A new method of classifying prognostic comorbidity in longitudinal studies: development and validation. J Chronic Dis. 1987; 40:373-83. 
https://doi.org/10.1016/0021-9681(87)90171-8

PMID:3558716

48. Chou WC, Chang PH, Chen PT, Wang HM, Yeh KY, Lu $\mathrm{CH}$, Hung YS, Tung-Chieh Chang J, Tsang NM, Ho YW, Chen SY, Lee SH, Hung CY, et al. Clinical Significance of Vulnerability Assessment in Patients with Primary Head and Neck Cancer Undergoing Definitive Concurrent Chemoradiation Therapy. Int J Radiat Oncol Biol Phys. 2020; 108:602-11. https://doi.org/10.1016/j.ijrobp.2020.01.004 PMID:31987971

49. National Cancer Institute. Common Terminology Criteria for Adverse Events (CTCAE) Version 4.0. 2009. https://evs.nci.nih.gov/ftp1/CTCAE/CTCAE 4.03/CTC AE 4.03 2010-06-14 QuickReference 5x7.pdf. 